\title{
STABILITY ANALYSIS OF EARTH DAM SLOPES SUBJECTED TO EARTHQUAKE USING ERT RESULTS INTERPRETATION
}

\author{
Eko Andi Suryo \\ Lecturer / Department of Civil Engineering, Faculty of Engineering / \\ University of Brawijaya
}

\begin{abstract}
Earth Dam stability can be affected significantly by the existence of excessive leakage. This is due to decreasing of shear strength of the dam material and additional overturning moment. In such scenario, the non-destructive soil investigation method is needed to analyze the stability of earth dam in current condition. This paper examines the use of Electrical Resistivity Tomography (ERT) to investigate soil layers and to measure parameters of soil shear strength indirectly. First survey was carried out at dam crest and downstream using Wenner Configuration along profile lines at electrode spacing of $5 \mathrm{~m}$. There were 5 profile lines of $180 \mathrm{~m}$ long each and $10 \mathrm{~m}$ distance of spacing. Furthermore, two profiles lines at weak cross-section based on its resistivity soil values were undertaken. Laboratory tests were conducted to determine relationship between resistivity value, moisture content, cohesion and angle of friction for each type of dam materials. From the ERT results and lab testing, a model dam can be obtained using current material parameters to perform stability analysis of dam subjected to earthquake. The lowest FOS was found at the upstream side about 1.15 and at the downstream side about 1.14 after applying seismic load of 100 years return period.
\end{abstract}

Keywords: Stability Analysis, ERT,resistivity, leakage, dam

\section{INTRODUCTION}

The most common problem in earth dams is abnormal seepage or excessive leakage that may cause dam failure [1]. Inspite of the facts that normal seepage throught the earth dam body is planned process, anomalous seepage may occurs by developing preferential flow paths in the dam body [2]. The existence of this excessive leakage can initiate instability of slope since the shear strength in current condition may be decreased.

Analysis of slope stability needs subsurface soil parameters that usually provided from soil investigation using wash drilling to gather soil samples. Considering the risk of excessive leakage, wash drilling should not being applied in the dam body investigation. Suggestion is being made to apply non-destructive geophysical methods, such as Electrical Resistivity Tomography (ERT), especially at the reconnaissance stage [3].

The ERT method can facilitate early detection or diagnosis of anomalous phenomena [4], determine the depth of water in saturated zone and detect groundwater flow pattern $[5,6]$. The ERT method identify soil resistivity that affected by degree of saturation, porosity, permeability, ionic content of the pore fluids, and clay content. Water seepage through a dam would be detected as a low resistivity using this electrical method [7, 8]. Furthermore, soil type can be determined by validating resistivity value with soil strength parameters that derived from laboratory tests [9].

This paper presents a case study to demonstrate the use of ERT results to interprete subsurface soil at Selorejo Earth Dam as introduced materials in stability slope analysis subjected to earthquake. The analysis undertaken considered the dynamic load due to earthquake, the saturated hydraulic conductivity of the embankment soil and the effect of in-situ properties of dam materials. Slope modelling for this analysis is made by introducing the most critical section of the dam that selected due to its low value of soil resistivity. The effect of pore-water pressures 
or transient seepage on the slope stability were analysed by coupling SEEP/W [10] with SLOPE/W [11]. The outcomes from this study could develop the basis for determining a safe method for surveying soil layers in order to undertake stability analysis for Indonesian Earth Dams.

\section{MODEL DAM AND ANALYSIS}

In this study, dam configuration shown in Fig. 1 and as built material properties listed in Table 1 were used. All geometries dimensions and material properties of earth dam were analyzed based on the data provided by the Perum Jasa Tirta I Malang. First ERT survey was carried out using Wenner Configuration along the profile line at inter electrode spacing of $5 \mathrm{~m}$. There were 5 profile lines of $180 \mathrm{~m}$ long each and $10 \mathrm{~m}$ distance of spacing. This reconnaissance stage using ERT was undertaken to investigate the soil subsurface related to abnormal seepage or piping in the body of dam materials. In the case of excessive seepage inside a dam body, it will be detected as low value of soil resistivity. Since low resistivity can indicate the low density of soil material, the stability of soil slope may be in critical state. Therefore, two additional ERT surveys were undertaken by crossing perpendicular to the previous profile lines to obtain more detail identification of subsurface soil at low resistivity zone.

To analyse stability of slope of the dam in current condition, soil parameters of the most critical section is needed. In this study, soil parameters at critical section were defined from laboratory soil test. Some selected soil tests (grain size distribution, water content test and direct shear test) were undertaken on soil samples taken from the origin quarry of dam material that then being designed its resistivity value following ERT results by changing the water content. This soil test results then were assigned as recent material properties in critical section of the dam. The combined model representing the critical section of the dam body was made by combining as-built drawing model and soil layer from ERT result interpretation.

The analysis in this study includes transient seepage analysis to determine porewater pressures and stability analysis of dam slope using Fellenius and Bishop Methods. Automatic coupled mode was designed for both analyses by applying seismic load. Each material zone in the analysis was assumed to be homogeneous and isotropic. If requirement soil parameter of the dam materials for the analysis is not available then it will be estimated using provided typical data in the software [12]. According to the Dam Safety Manual in Indonesia, factor of safety of dam slope should not less than 1.2 [13]

Coefficient of earthquake peak acceleration is taken from Indonesia's Earthquake Zoning Map of year 2010 with a return period of 50 years and 100 years. For Malang residence (the location of studied dam), the coefficient were taken $0.25 \mathrm{~g}$ for a return period of 50 years and $0.3 \mathrm{~g}$ for a return period of 100 years. By taking into account the amplification factor based on the medium rock type at 1.2 and factors influence of freefield at 0.7 [13], then obtained coefficient of earthquake peak acceleration for this study are $0.21 \mathrm{~g}$ for a return period of 50 years and $0.252 \mathrm{~g}$ for a return period of 100 years.

\section{RESULTS AND DISCUSSION 3.1 Soil layer modelling using ERT result interpretation}

First five ERT surveys were carried out along the dam crest and downstream site to investigate the zone of low value of soil resistivity as the weak site. Then, two profile lines were conducted across the weak section of the dam body. Plotting of the profiles lines is presented in Fig.2. The results of ERT using Wenner configuration survey are shown in Fig.3.

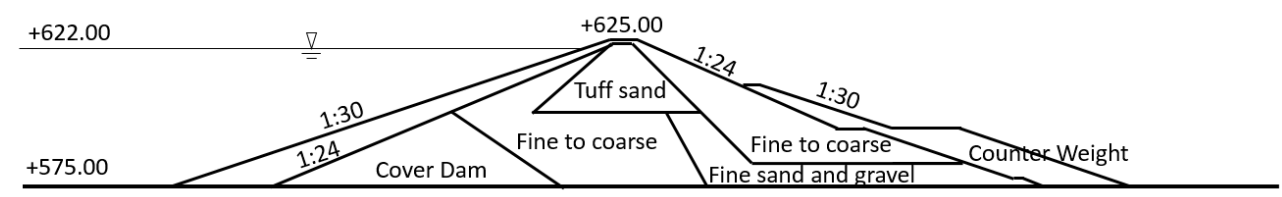


Fig. 1. Geometry and material zones of the earth dam

Table 1. Initial properties of the earth dam material

\begin{tabular}{|c|c|c|c|c|c|}
\hline $\begin{array}{c}\text { Soil } \\
\text { Properties }\end{array}$ & $\begin{array}{c}\text { Clay } \\
\text { Loam }\end{array}$ & Tuff sand & $\begin{array}{c}\text { Sand and } \\
\text { Gravel } \\
\text { (Coarse) }\end{array}$ & $\begin{array}{c}\text { Fine sand } \\
\text { \& gravel }\end{array}$ & $\begin{array}{c}\text { Clayey Loam } \\
\text { (Counterweight) }\end{array}$ \\
\hline$\gamma(\mathrm{t} / \mathrm{m} 3)$ & 1,250 & 1,603 & 2,072 & 1,772 & 1,136 \\
\hline $\mathrm{C}(\mathrm{t} / \mathrm{m} 2)$ & 6,16 & 3,05 & - & - & 6,77 \\
\hline $\mathrm{f}\left({ }^{\circ}\right)$ & $20^{\circ} 46^{`}$ & $41^{\circ} 30^{`}$ & - & - & $17^{\circ} 28^{\prime}$ \\
\hline $\mathrm{k}(\mathrm{cm} / \mathrm{sec})$ & $3,9 \times 10^{-6}$ & $1,5 \times 10^{-5}$ & $0,95 \times 10^{-4}$ & $1,933 \times 10^{-6}$ & - \\
\hline
\end{tabular}

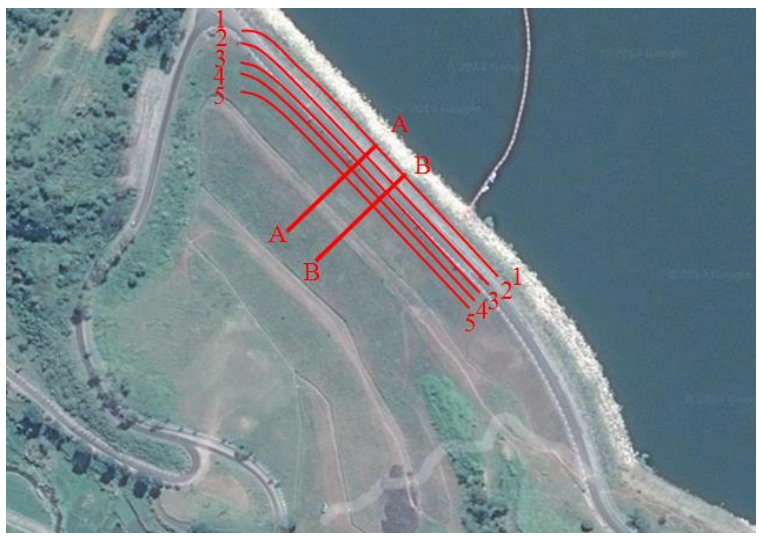

Fig. 2. ERT profile lines plotting on the body of the earth dam

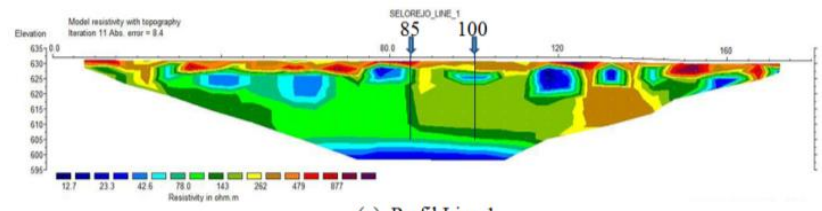

(a) Profil Line 1

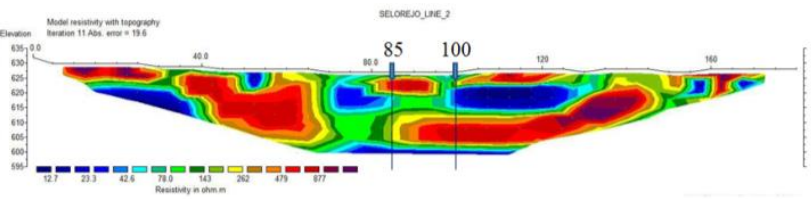

(b) Profil Line 2

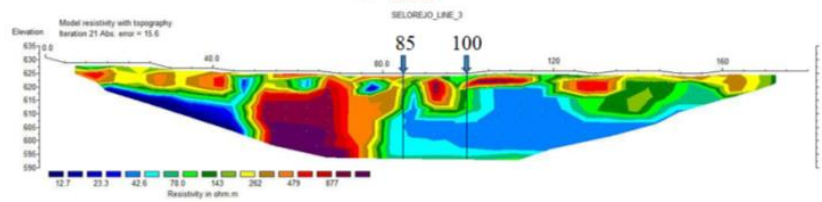

(c) Profil Line 3

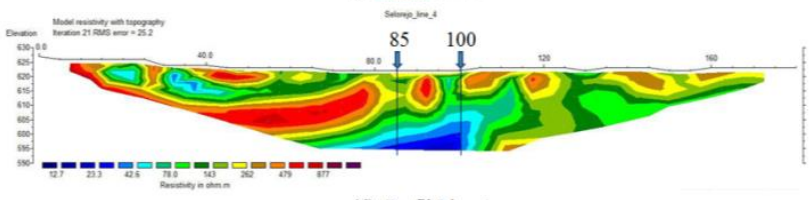

(d) Profil Line 4

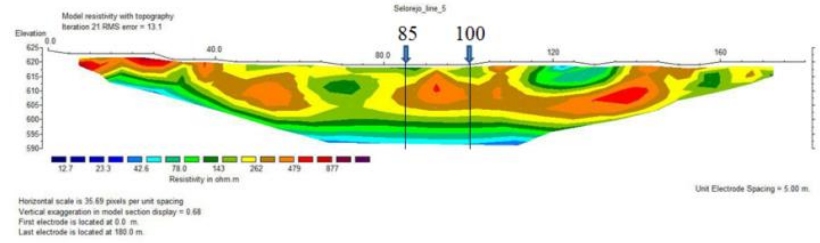

(e) Profil Line 5

Fig. 3. Soil resistivity imaging along the body of the earth dam 
Fig. 3 presents the soil resistivity distribution of subsurface soil in the study area. A significant variation of soil resistivity at different depths along the profile lines can be observed. The soil resistivity in the area is ranging from 10 to $880 \Omega \mathrm{m}$, indicating wide variation in soil type, clay content of soil, porosity, and water content [9]. There are some local zones with very low resistivity $(10-50$ $\Omega \mathrm{m})$. These zones could be identified as possible excessive leakage. A simplification for the modelling need to be taken due to the significant variation of the resistivity soils values by dividing the value into three groups: high value (R1) for $262 \Omega \mathrm{m}$ above, middle value (R2) for $42,6 \Omega \mathrm{m}$ to $262 \Omega \mathrm{m}$ and low value (R3) for $12,7 \Omega \mathrm{m}$ to $42,6 \Omega \mathrm{m}$. Then, the average of $\mathrm{R} 1, \mathrm{R} 2$ and $\mathrm{R} 3$ are $27,65 \Omega \mathrm{m}$, $170 \Omega \mathrm{m}$, and $569,5 \Omega \mathrm{m}$, respectively.

Since the soil resistivity is affected by clay content and soil density in addition to soil water content, it is possible to use the low value of soil resistivity to detect location of excessive leakage in the subsoil. From Fig. 3, it can be found that the significant low resistivity values are located at cross-section of $+85 \mathrm{~m}$ and $+100 \mathrm{~m}$. Then, Fig. 4 shows the ERT results image on cross-section +85 that has possible leakage at some areas. The cross-sectional model dam representing the critical section of the dam body is made by plotting the zone of the soil resisitivity value groups on the as-built drawing model dam, as representing in Fig.5.

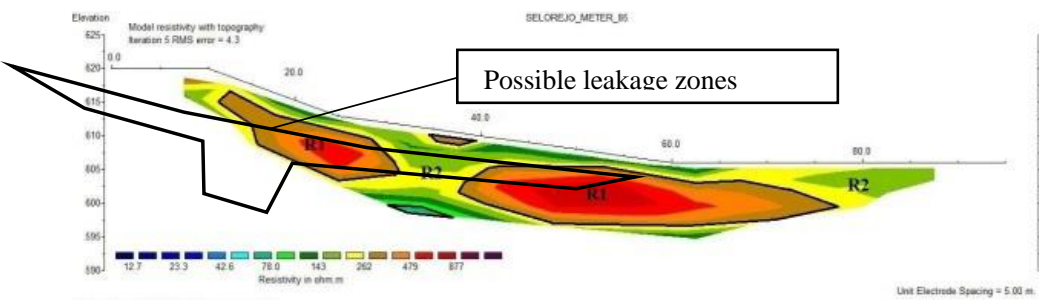

Fig. 4. Soil resistivity imaging along cross-section line $85 \mathrm{~m}$

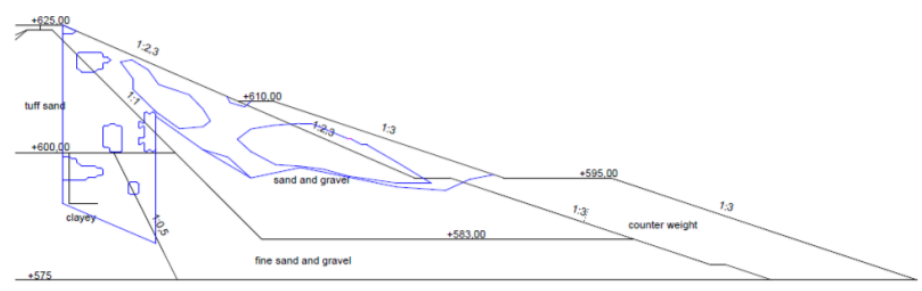

Fig. 5. Cross-section of model on line $85 \mathrm{~m}$

In the area that can be covered by ERT depth, the soil parameters were taken from laboratory tests, whereas in areas beyond the ERT depth, soil parameters from The Completion Report on Selorejo Dam Project (1976) by Jasa Tirta Public Coorporation were adopted. Some selected soil tests (grain size distirbution, water content test and direct shear test) were undertaken on soil samples taken from the origin quarry of dam material that being designed its resistivity value following ERT results by changing the water content. These soil test results then were assigned as current material properties in critical section of the dam as presents at Fig. 6 to Fig. 10 and

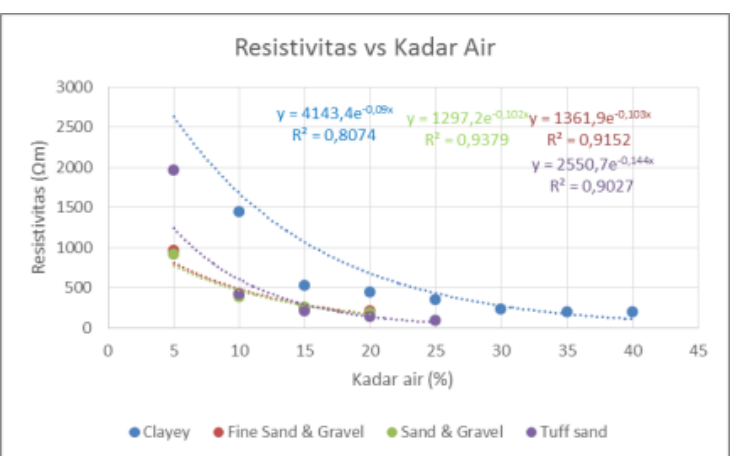

Fig. 6. Variation of soil resistivity value with water content resumes at Table 2 . 


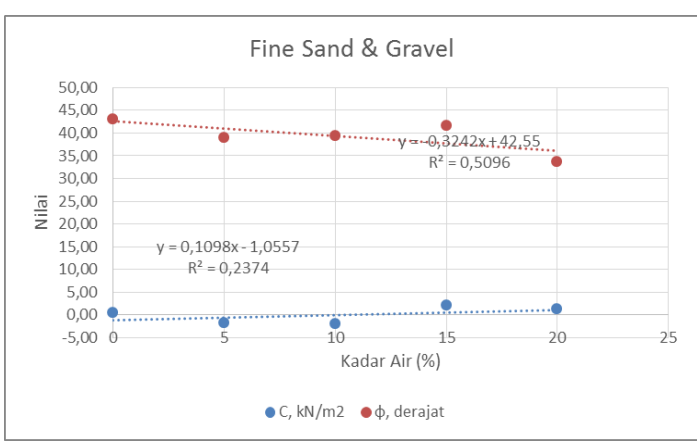

Fig. 7. Variation of $\mathrm{c}$ and $\square$ value with different water content on Fine Sand \& Gravel

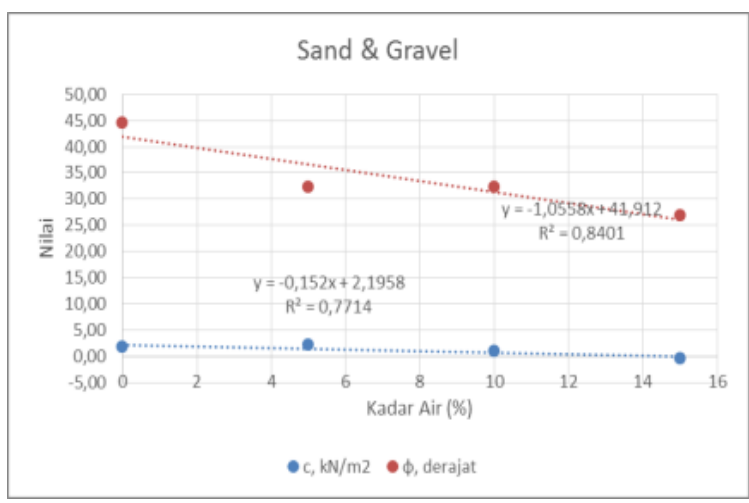

Fig. 8. Variation of $\mathrm{c}$ and $\square$ value with different water content on Sand \& Gravel

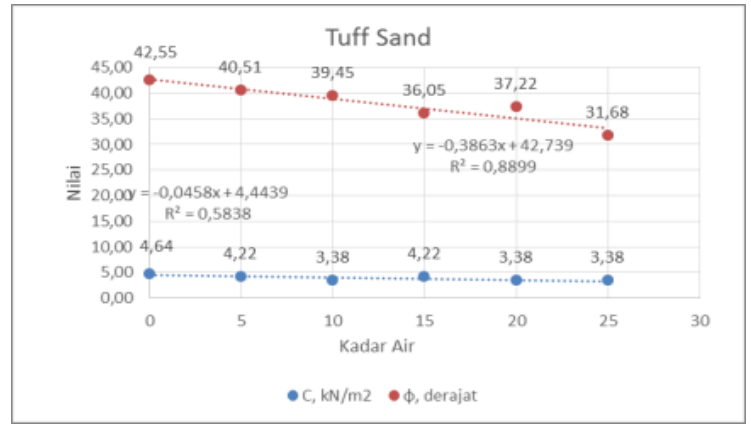

Fig. 9. Variation of $\mathrm{c}$ and $\square$ value with different water content on Tuff Sand

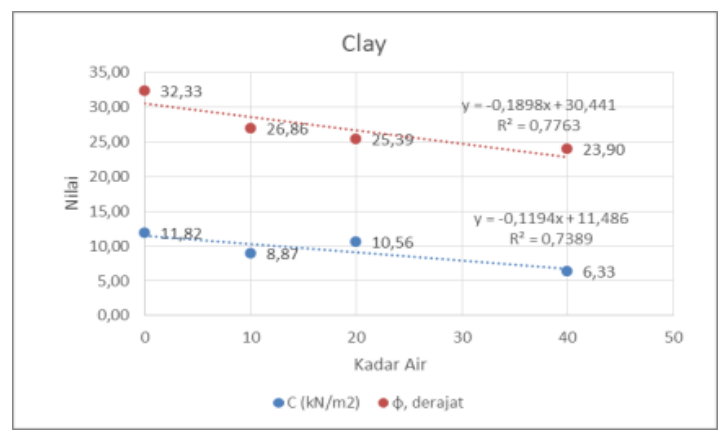

Fig. 10. Variation of $\mathrm{c}$ and $\square$ value with different water content on Clay

Table 2. Soil properties of the earth dam material on the weak cross-section

\begin{tabular}{|c|c|c|c|c|c|c|c|c|c|}
\hline Resistivitas $(\Omega \mathrm{m})$ & \multicolumn{3}{|c|}{569,5} & \multicolumn{3}{|c|}{170} & \multicolumn{3}{|c|}{27,65} \\
\hline Parameter & \multirow{2}{*}{ wc (\%) } & \multirow{2}{*}{$\underset{(t / m 2)}{C}$} & \multirow{2}{*}{$\varphi(0)$} & \multirow{2}{*}{ wc (\%) } & \multirow{2}{*}{$\begin{array}{c}\mathrm{C} \\
(\mathrm{t} / \mathrm{m} 2)\end{array}$} & \multirow{2}{*}{$\varphi(0)$} & \multirow{2}{*}{ wc (\%) } & \multirow{2}{*}{$\begin{array}{c}\mathrm{C} \\
(\mathrm{t} / \mathrm{m} 2)\end{array}$} & \multirow{2}{*}{$\varphi(0)$} \\
\hline Jenis Tanah & & & & & & & & & \\
\hline Clayey Loam & 22.05 & 8.85 & 26.26 & 35.48 & 7.25 & 23.71 & 55.66 & 4.84 & 19.88 \\
\hline F Sand and Gravel & 8.46 & - & 39.81 & 20.20 & - & 36.00 & 37.84 & - & 30.28 \\
\hline Sand and Gravel & 8.07 & - & 33.39 & 19.92 & - & 20.88 & 37.73 & - & 2.08 \\
\hline Tuff Sand & 10.41 & 3.97 & 38.72 & 18.81 & 3.58 & 35.47 & 31.42 & 3.00 & 30.60 \\
\hline
\end{tabular}

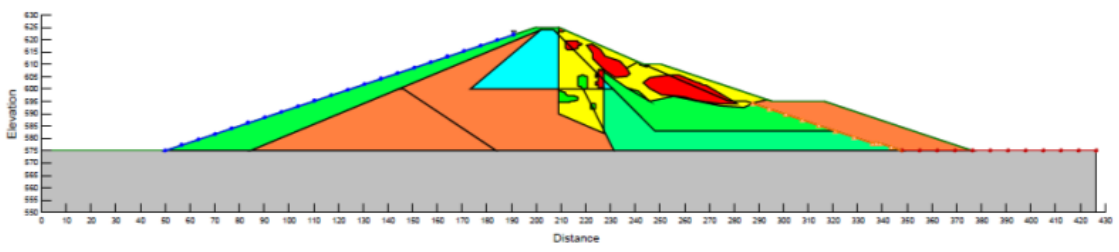

Fig. 11. Model dam using on cross-section $+85 \mathrm{~m}$ 


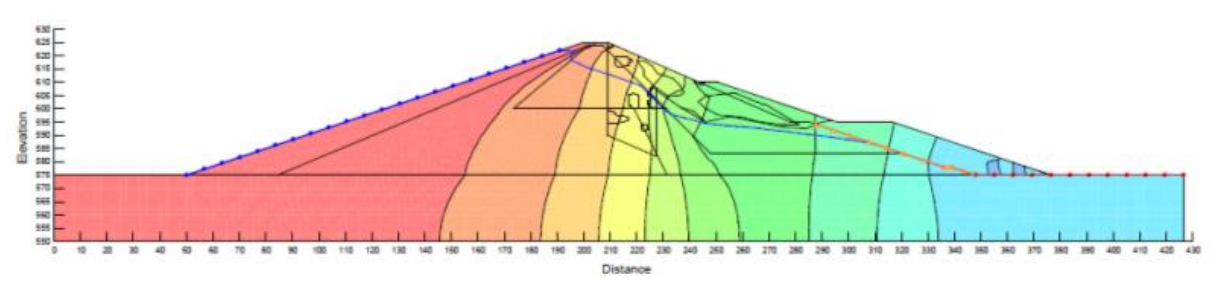

Fig. 12. Seepage analysis results on cross-section $+85 \mathrm{~m}$

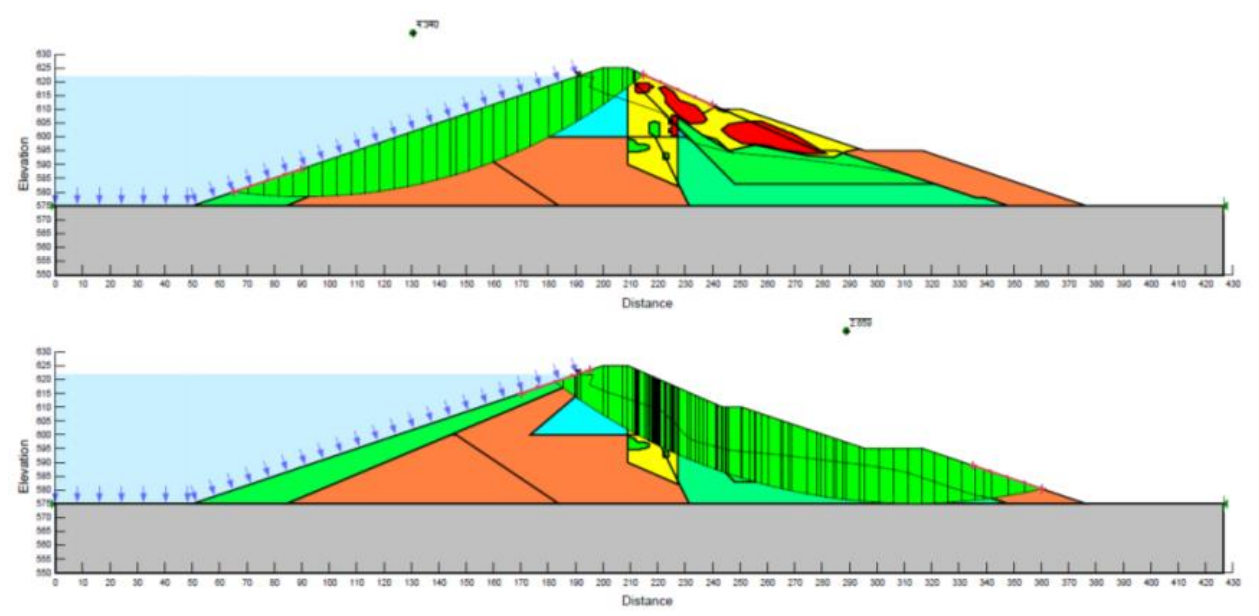

Fig. 13. Stability analysis results on cross-section $+85 \mathrm{~m}$ before applying Seismic load

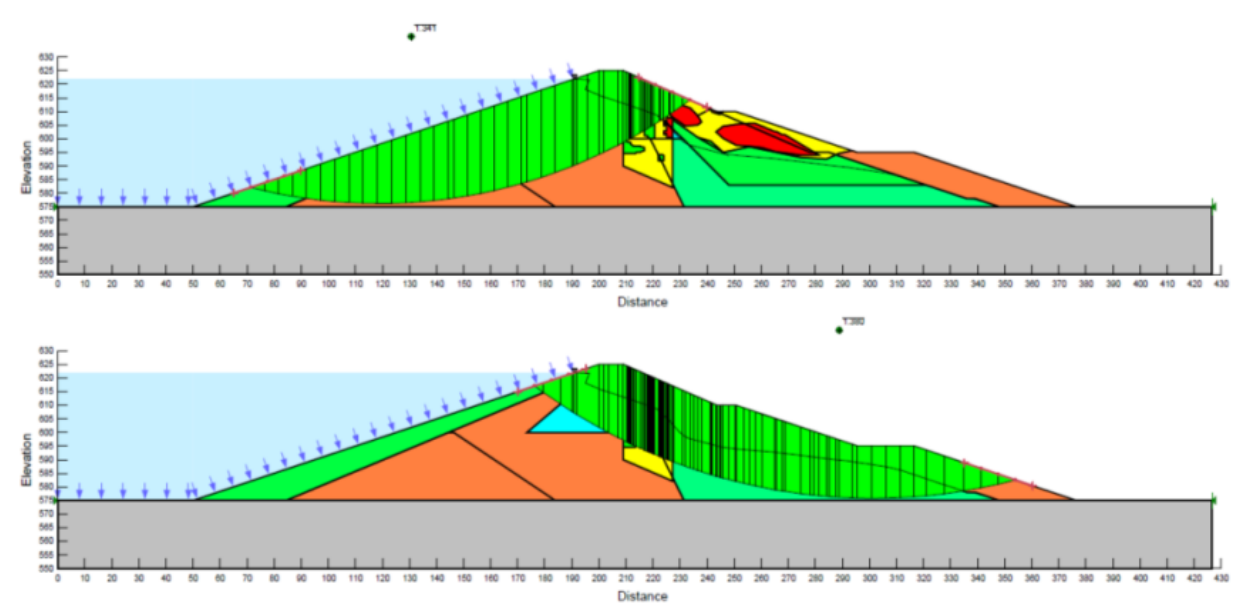

Fig. 14. Stability analysis on $+85 \mathrm{~m}$ after applying seismic load for a return period of 50 years

Table 3. Resume of variation of FOS after seismic loading

\begin{tabular}{|c|c|c|c|}
\hline \multicolumn{2}{|c|}{ Cross-section } & $\mathbf{+ 8 5 m}$ & $\mathbf{+ 1 0 0 m}$ \\
\hline \multirow{4}{*}{ upstream } & No Earthquake & 4.340 & 4.294 \\
\cline { 2 - 4 } & 50 years periode & 1.341 & 1.328 \\
\cline { 2 - 4 } & 100 years periode & 1.157 & 1.150 \\
\hline \multirow{4}{*}{ upstream } & No Earthquake & 2.659 & 2.249 \\
\cline { 2 - 4 } & 50 years periode & 1.380 & 1.247 \\
\cline { 2 - 4 } & 100 years periode & 1.252 & 1.140 \\
\hline
\end{tabular}




\subsection{Instability of earth dam slope due to earthquake}

The analysis used the cross-sectional model dam representing the critical section of the dam body as shown in Fig.11, for $+85 \mathrm{~m}$ section. Initial pore water pressure was measured using SEEP/W that simulating 2-D steady state seepage in the earth dam as presenting in Fig. 12.

Then, to analyse the stability of the dam, Fellenius method and Bishop method were employed by introducing seismic load $0.21 \mathrm{~g}$ for a return period of 50 years and $0.252 \mathrm{~g}$ for a return period of 100 years. The result from the stability analysis at cross-section $+85 \mathrm{~m}$ are presented in Fig.13 and Fig.14. All procedurs were applied as well for cross-section $+100 \mathrm{~m}$ that being resumed in Table 3 . It can be seen that the FOS decreases when seismic loading was applied in the analysis, Moreover, the FOS becomes lower than permitted value of 1.2 [13] when seismic load coeffisient of 100 years return periods was introduced.

\section{CONCLUSIONS}

The interpretation of ERT results incorporating with laboratory validation test results were employed in the stability analysis of the earth dam subjected to earthquake. The following conclusions were resumed from this study as follows:

1. Significant variation of soil resistivity at different depths along the ERT profile lines can be observed that can be used to detect subsurface soil layers.

2. Soil shear strength parameters in current conditions can be obtained by validating the soil resistivity value from ERT results with some laboratory tests.

3. When the weaker soil parameter from ERT result interpretation was introduced into model dam for stability analysis subjected to earthquake, the FOS of the dowstream slope is decreased significantly.

\section{REFERENCES}

[1] Malkawi A.I.H. and M. Al-Sheriadeh, "Evaluation and rehabilitation of dam seepage problems. A case study: Kafrein dam", Engineering Geology, 56(3), 200, pp.335-345

[2] Lee, J. Y., Choi, Y. K., Kim, H. S., \& Yun, S. T. "Hydrologic characteristics of a large rockfill dam: Implications for water leakage",
Engineering Geology, 80(1-2), 2005, pp. 4359.

[3] Craig R.F., "Craig's Soil Mechanics" 7th edition, Spon, Press. London, 2004.

[4] Voronkov, O. K., et al. "Geophysical methods and identification of embankment dam parameters." Proceedings of the 2nd International Conference on Site Characterization (ISC-2). 2004.

[5] Loke, M. H. "Electrical imaging surveys for environmental and engineering studies." $A$ practical guide to 2, 1999.

[6] M. H. Loke. Tutorial: $2 D$ and $3 D$ Electrical Imaging Surveys, 2004

[7] Johansson, Sam, and Torleif Dahlin. "Seepage monitoring in an earth embankment dam by repeated resistivity measurements." European Journal of Engineering and Geophysics 1,1996: pp.229-247.

[8] Aal, Gamal Z. Abdel, et al. "Geophysical Investigation of Seepage from an Earth Fill Dam, Washington County, MO." Journal of Applied Geophysics 44, 2004, pp. 167-180.

[9] Suryo, Eko Andi, et al. "Application of electrical resistivity method to detect deep cracks in unsaturated residual soil slope." Proceedings of AP-UNSAT 2011: 5th AsiaPasific Conference on Unsaturated Soils. Geotechnical Engineering Research and Development Center (GERD) Department of Civil Engineering, Faculty of Engineering Kasetsart University, Thailand, 2011.

[10] GEO-SLOPE International Ltd., Seepage Modeling with SEEP/W 2007: An Engineering Methodology (Alberta: GEO-SLOPE International Ltd., 2010)

[11] GEO-SLOPE International Ltd., Stability Modeling with SLOPE/W 2007: An engineering methodology (Alberta: GEOSLOPE International Ltd., 2010).

[12] Souliyavong, T., et al. "Factors affecting the stability analysis of earth dam slopes subjected to reservoir drawdown." Proceedings of the Second International Conference on Geotechnique, Construction Materials and Environment. The GEOMATE International Society, 2012.

[13] Departemen PU, "Analisa Dinamik Bendungan Urugan", Direktorat Jenderal SDA, Jakarta, 2008 